\title{
Population genetics of Norway spruce (Picea abies Karst.) at regional scale: sensitivity of different microsatellite motif classes in detecting differentiation
}

\author{
Ivan ScotTi ${ }^{\mathrm{a}, \mathrm{b} *}$, Gianpaolo PAGLIA ${ }^{\mathrm{a}}$, Federica MAGNI $^{\mathrm{a}}$, Michele MoRGANTE ${ }^{\mathrm{a}}$ \\ a Dipartimento di Scienze Agrarie ed Ambientali, Università di Udine, Via delle Scienze 208, 33100 Udine, Italy \\ ${ }^{\mathrm{b}}$ Current address: INRA, UMR ECOFOG, Campus agronomique, BP 709,
}

97387 Kourou Cedex, French Guiana

(Received 28 February 2005; accepted 27 March 2006)

\begin{abstract}
Four populations of Norway spruce (Picea abies Karst.) were screened using nine nuclear microsatellite markers (three trinucleotides and six dinucleotides) and four chloroplast markers (all mononucleotides). Marker classes were compared for their variability, mutation rate and ability to detect differentiation between stands. Dinucleotide markers proved to be the most variable group and chloroplast stretches the least variable, with differences in mutation rate between the former and the latter spanning over two orders of magnitude. Variability correlated to the number of repeats but not to the absolute length of the microsatellite region. The different marker classes were combined with two different measures of genetic distance in order to investigate the performance of markers and evolutionary models for the study of genetic variation in natural populations of Norway spruce. Weir and Cockeram's $\mathrm{F}_{\mathrm{ST}}$ generally performed better in this clear-cut, four-population model study. Chloroplast haplotypes turned out to be the most sensitive marker system, being able to differentiate populations and to detect differences in genetic variability between sub-regions.
\end{abstract}

conifers / SSR / divergence / statistical testing / genetic distance

Résumé - Génétique des populations d'épicéa (Picea abies Karst.) à l'échelle régionale : sensibilité de différent motifs microsatellites dans la détection de la différenciation. Quatre populations d'épicéa (Picea abies Karst.) ont été analysées avec neuf marqueurs microsatellite nucléaires (trois trinucléotidiques et six dinucléotidiques) et quatre marqueurs chloroplastiques (tous mononucléotidiques). La variabilité, le taux de mutation et la performance dans la détection de la différentiation entre sites de ces classes de marqueurs ont été comparées. Les marqueurs dinucléotidiques ont montré la plus forte variabilité, et les marqueurs chloroplastiques la plus faible, avec une différence en taux de mutation d'un facteur cent entre les deux classes. La variabilité est corrélé avec le nombre de répétions mais n'est pas corrélé avec la taille de la répétition. Les différentes classes des marqueurs ont été combinées avec deux mesures de distance génétique pour analyser les effets du choix du marqueur et du model évolutif sur l'étude de la variabilité génétique des populations naturelles d'épicéa. Le $\mathrm{F}_{\mathrm{ST}}$ de Weir et Cockeram a produit en général les meilleurs résultats dans cette simple étude sur quatre populations. Les haplotypes chloroplastiques ont montré la plus grande efficacité, permettant de distinguer les régions et les populations à l'intérieur des régions.

conifères / SSR / divergence / test statistique / distance génétique

\section{INTRODUCTION}

Norway spruce is a conifer species characterised by a wide natural range, covering most of continental Europe, by high levels of heterozygosity, and by low levels of population differentiation even at large geographical distances. Studies based on molecular markers with low allelic diversity (isozymes [15]; SCARs [25]) generally show an average among-population $\mathrm{F}_{\mathrm{ST}}$ close to 5\%. This does not apply, however, to maternally-inherited (mitochondrial) markers, which on the contrary can detect high levels of differentiation $[9,27]$, due to limited seed dispersal and consequently increased population structuring. For biparentally or paternally inherited loci, trends of differentiation or clines of allele frequencies are hardly detectable, so that it is generally hard to make phylogeographic inferences based on molecular marker data. The

\footnotetext{
* Corresponding author: ivan.scotti@kourou.cirad.fr
}

introduction of markers with a higher variability (expressed as number of observed alleles, for a given sample size), such as nuclear microsatellites, may help in the identification of local exceptions to these general features, as well as in the detection of range-wide migration and colonisation routes. Indeed, the application of chloroplast microsatellites has allowed Bucci and Vendramin [2] to identify sections of the range of Norway spruce confirming the colonisation routes hypothesised by Lagercrantz and Ryman [15]. Chloroplast markers combine average variability (intermediate between nuclear microsatellites and isozymes) with the possibility to identify (non-recombining) haplotypes, which magnify their power in the detection of differentiation.

Nuclear microsatellite markers have slightly different features than chloroplast loci, since they are less sensitive to variations in population effective size (due to diploidy), show a generally higher variability, and allow the assessment of 
heterozygosity. Moreover, nuclear chromosomes display virtually all repeat units made of 1 to 5 nucleotides. This allows the study of the behaviour of each of these repeat classes in population studies.

Nuclear SSR markers for Norway spruce have been developed from genomic dinucleotide and trinucleotide sequences [19, 23, 24] and from EST-derived dinucleotide stretches [22]. Their variability and power in the detection of differentiation are evaluated here in a set of four populations distributed in the Eastern part of the Alps, chosen so that, when taken pairwise, they cover increasing levels of geographic isolation. Pollen-mediated gene flow in conifers is generally strong, as deduced by genetic distance estimates [15,25], and genetic differentiation appears to be linearly correlated with geographical distances at least on a scale of few tens to few hundred kilometers ([15] and this paper). At very short distances, pollen flow is very effective in amalgamating populations ([3] and references therein). Therefore, we expect populations only few kilometres apart to behave genetically as a single unit, while more distant populations should reflect more strictly an island model. We investigate here the ability of different classes of SSR markers to detect differentiation among populations at increasing geographic distances, analysing the effects of repeat type and mutation rate on the resulting pattern of differentiation.

A further source of variation in the estimates of genetic differentiation, besides the use of different marker classes, is represented by the choice of the genetic distance estimator (and of its underlying evolutionary model). The use of $\mathrm{F}_{\mathrm{ST}}$ and $\mathrm{R}_{\mathrm{ST}}$ in the analysis of natural populations has been recently reviewed by Balloux and Lugon-Moulin [1]. Particular combinations of markers and genetic distance estimators may lead to failures in the detection of actual genetic differentiation as well to the detection of apparent genetic differentiation where there is none. This may be particularly true for small sample sizes and/or when applying a limited number of markers (see [1] and citations therein). This corresponds, in statistical terms, respectively to false negative and false positive results. Ideally, marker systems should be "calibrated" so that such errors are avoided in real cases, using a clear-cut population sampling scheme as a reference.

In this article we compare the results obtained by three classes of microsatellites: nuclear dinucleotide SSRs, nuclear trinucleotide SSRs and chloroplast SSRs. Marker classes are shown to correspond to mutation rate classes as defined by the statistical analysis of genetic variation [4]. This analysis also provides an estimate of relative mutation rates among loci. By analysing populations at increasing geographic distances, we explored under which conditions different marker types, in combination with genetic distance estimators, fail to detect differentiation (false negative results) or detect significant differentiation between undifferentiated populations (false positive results) of Norway spruce.

Our results provide guidelines on how to apply microsatellite marker data to the analysis of population differentiation in conifers, and suggest ways to avoid false inferences on the geographical structuring of genetic diversity.

\section{MATERIALS AND METHODS}

Four populations, geographically clustered in two groups of two populations, have been chosen so that two (Tarvisio and Fusine) are found in the same valley at short distance $(3 \mathrm{~km})$, and the other two (Val Meledrio and Val di Fiemme) lie in two nearby valleys $(30 \mathrm{~km}$ apart), separated by two ranges of mountains and by the Adige valley, at a large distance from the first pair (Fig. 1a). Within-pair genetic distances are therefore expected to differ between the two pairs, with the former actually belonging to a single panmictic unit, and the latter deriving from two separated units. This offers an empirical pattern of expected pairwise population differentiation. We expect an "insensitive" combination of markers and genetic distance measures to detect no differentiation, a "sensitive" system to detect differentiation for the four pairs of distant populations, a "very sensitive" system to also detect separation between Val Meledrio and Val di Fiemme, while an "hypersensitive" combination would detect differentiation for all pairwise comparisons, including for the pair Tarvisio-Fusine, for which no differentiation at all should be detected.

SSR data have been analysed using two most commonly used measures of genetic distance involving within-population expected heterozygosity, $\mathrm{F}_{\mathrm{ST}}[18,33]$ (based on the Infinite Allele Model [13]) and $\mathrm{R}_{\mathrm{ST}}$ [26] (based on the Stepwise Mutation Model; [14]). The results are compared to the grouping of the populations in two clusters, which is expected based on the observed distribution of microsatellite variability for Norway spruce in the Alps, and to the expectation that Fusine and Tarvisio stands tend to merge into a single population due to their proximity.

Seeds were collected from trees in the four stands. DNA was extracted from one-week old embryos (36 per population for Tarvisio and Fusine) or from megagametophytes (from 36 mother trees per population for Val Meledrio and Val di Fiemme) following the protocol of Doyle and Doyle [5] with modifications. In the latter case, DNA was pooled by mother tree, in order to reconstitute mother tree genotypes (six megagametophytes per mother tree).

PCR conditions, gel runs and data collection were as described in [19] for dinucleotide markers (SpAGC1, SpAGC2, SpAGG3, SpAC1F7, SpAGD1, SpAC1H8), and as described in [21] for trinucleotide markers (EATC1B02, EATC1E03, and EATC1G02).

The protocol for chloroplast SSRs (Pt30204, Pt45002, Pt100783, and Pt110048) was as described in Vendramin et al. [31]. Population diversity estimates were computed using either the POPGENE [34] or the GENEPOP [18] program. Hardy-Weinberg equilibrium was tested through a G-test (95\% limit). $\mathrm{F}_{\mathrm{ST}}$ and $\mathrm{R}_{\mathrm{ST}}$ were computed using the ARLEQUIN program [19]. Statistical significance of pairwise population differentiation was tested by permutation (with $N=1000$ ). The same software was also used to carry out the Analysis of Molecular Variance (AMOVA [7]). Significance of variance components was tested by permutation $(N=1000)$. The variance of $\mathrm{F}_{\mathrm{ST}}$ and $\mathrm{R}_{\mathrm{ST}}$ were compared to the variance expected under drift alone by a LewontinKrakauer test [16].

Chloroplast SSR scores were converted into haplotypes and treated the same way as the nuclear SSR data. A haplotype network [29] was also obtained using ARLEQUIN, and tested statistically for phylogeographic structure.

For the analysis of mutation rates, the analytical framework described in Chakraborty et al. [4] was followed. Chakraborty et al. [4] have shown that mutation rates are proportional to variances in allele size, provided that a standard analysis of variance (ANOVA) proves that there is no population history effect on allele size variance. In the present study both diploid and haploid loci are considered. Therefore, 
(a)
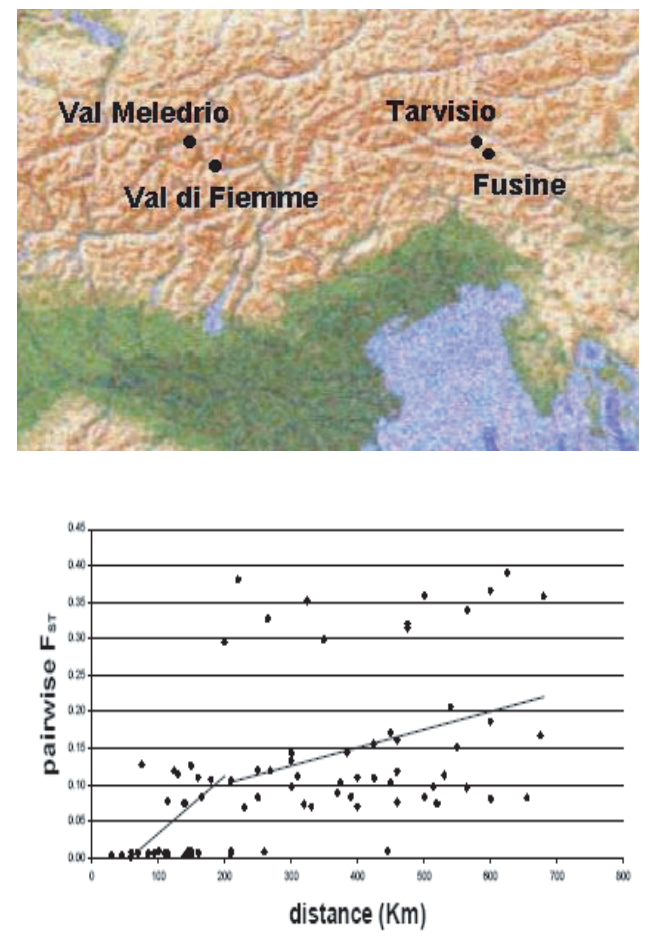

(c) (b)
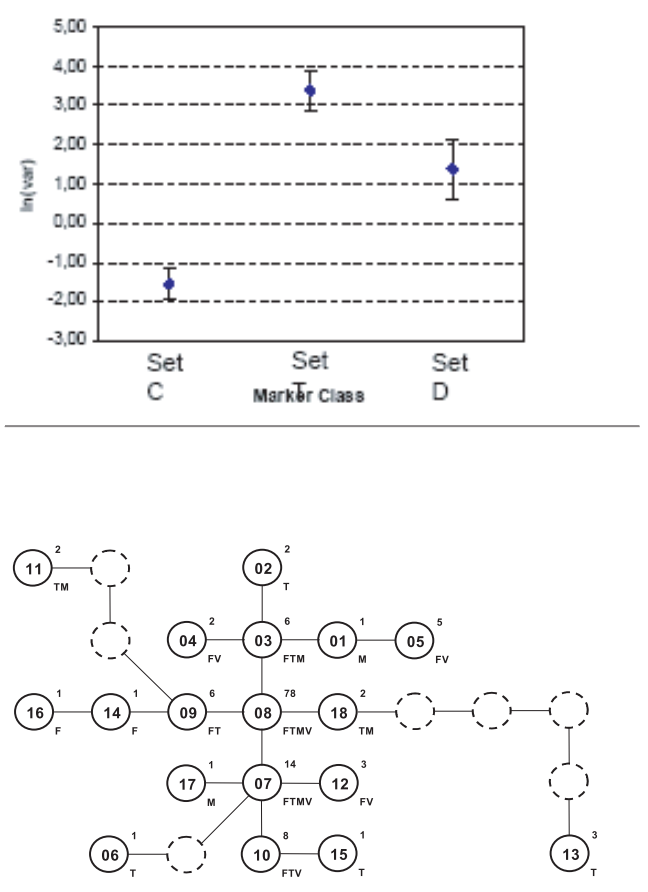

(d)

Figure 1. (a) Map of the Eastern Alpine range with the position of the four sampled populations. Co-ordinates: Fusine, $46^{\circ} 29^{\prime} \mathrm{N}, 13^{\circ} 39^{\prime}$ E; Tarvisio, 46 $30^{\prime} \mathrm{N}, 13^{\circ} 35^{\prime} \mathrm{E}$; Val di Fiemme, 46 $16^{\prime} \mathrm{N}, 11^{\circ} 32^{\prime} \mathrm{E}$; Val Meledrio, $46^{\circ} 28^{\prime} \mathrm{N}, 10^{\circ} 52^{\prime}$ E. (b) Mean (dots) of the natural logarithm of allele size variances for the three sets of loci (see text) and $95 \%$ confidence intervals (bars). Natural logarithms are displayed instead of original values for clarity of visualisation. According to the explanation given in the text, displayed $\ln (\text { var })_{C P}$ is increased by a factor $\ln 2$ to allow direct comparison with figures obtained from nuclear loci. (c) Relationship between $\mathrm{F}_{S T}$ and geographical distance for Alpine populations of Norway spruce. Two regression lines are shown, following the frame for the interpretation of data suggested by Hutchinson and Templeton (1999). (d) Network of chloroplast haplotypes. Numbers at the top right of each circle represent the absolute frequency of each haplotype in the global population; letters at the bottom right indicate the populations in which the haplotypes were observed $(\mathrm{F}=\mathrm{Fusine}$; $\mathrm{T}=$ Tarvisio; $\mathrm{M}=$ Val Meledrio; V = Val di Fiemme).

equation (2) of Chakraborty et al. [4] has been modified, for chloroplast loci, to $\mathrm{V}=2 \mathrm{~N} v \psi^{\prime \prime}(1)$, in order to take into account haploid population size. Consequently, ratios of variance $(\mathrm{V})$ and mutation rates $(v)$, for any pair of nuclear (n) and plastidial (p) microsatellites, are related through the formula: $\mathrm{V}_{n} / \mathrm{V}_{\mathrm{p}}=n_{n} /\left(2 v_{p}\right)$. In the following analyses, this multiplication factor is included in the constants that allow computation of ratios of set-specific mutation rates according to Chakraborty et al. [4].

\section{RESULTS}

Diversity parameters and global $\mathrm{F}_{\mathrm{ST}}$ values are shown in Table I. The variability was higher for the dinucleotide SSRs (10 to 41 alleles per locus) than for the trinucleotide loci (6 to 7 alleles per locus), while only 2 to 4 alleles per locus were found at the chloroplast loci, with a total of 18 haplotypes (out of 96 potential assortments of alleles). The chloroplast loci therefore showed, taken as haplotypes, intermediate variability compared to the nuclear loci. Global $\mathrm{F}_{\mathrm{ST}}$ values were generally very low (Tab. I), an order of magnitude smaller than the figures reported in other papers $[15,25]$.

Heterozygote deficiency was detected for all loci (Tab. I), though only for the three trinucleotide loci this determined a significant departure from Hardy-Weinberg equilibrium, either within population or in the global sample. Homozygote excess has been so far shown in conifers mostly in juveniles [17], and it is possible that the type of tissue we have used for this study (seedlings or pools of megagametophytes) shows the same type of departure from equilibrium. However, only EATC1G02 showed distortion at the population level in 3 populations out of 4. EATC1B02 and EATC1E03 displayed departure from Hardy-Weinberg equilibrium in the global population, but not in single stands. The presence of equilibrium within the populations associated with departure from equilibrium across populations (Wahlund effect [8]) is an indication of population subdivision. This feature is only apparent for the trinucleotide loci, while none of the dinucleotide SSRs gave indications of population fragmentation. The presence of null 
Table I. Basic parameters of the markers as computed on the single populations.

\begin{tabular}{|c|c|c|c|c|c|c|c|}
\hline \multirow[b]{2}{*}{ Locus } & & \multirow[b]{2}{*}{$\mathrm{F}$} & \multicolumn{2}{|c|}{ Populations } & \multicolumn{3}{|c|}{ Population means } \\
\hline & & & $\mathrm{T}$ & $\mathrm{V}$ & $\mathrm{M}$ & & Overall \\
\hline $\begin{array}{l}\text { EATC1G02 } \\
\left(\mathrm{F}_{S T}=0.00\right)\end{array}$ & $\begin{array}{l}\mathrm{n}_{a} \\
\mathrm{H}_{o} \\
\mathrm{H}_{e} \\
\text { ANR } \\
\text { ASL }\end{array}$ & $\begin{array}{c}5 \\
0.31 \\
0.47\end{array}$ & $\begin{array}{c}4 \\
0.18 \\
0.47\end{array}$ & $\begin{array}{c}6 \\
0.18 \\
0.44\end{array}$ & $\begin{array}{c}5 \\
0.28 \\
0.59\end{array}$ & $\begin{array}{l}5.00(0.82) \\
0.24(0.07) \\
0.49(0.07)\end{array}$ & $\begin{array}{l}23.05 \\
69.15\end{array}$ \\
\hline $\begin{array}{l}\text { EATC1B02 } \\
\left(\mathrm{F}_{S T}=0.00\right)\end{array}$ & $\begin{array}{l}\mathrm{n}_{a} \\
\mathrm{H}_{o} \\
\mathrm{H}_{e} \\
\text { ANR } \\
\text { ASL }\end{array}$ & $\begin{array}{c}6 \\
0.41 \\
0.41\end{array}$ & $\begin{array}{c}6 \\
0.42 \\
0.46\end{array}$ & $\begin{array}{c}5 \\
0.49 \\
0.51\end{array}$ & $\begin{array}{c}6 \\
0.40 \\
0.46\end{array}$ & $\begin{array}{l}5.75(0.50) \\
0.43(0.04) \\
0.46(0.04)\end{array}$ & $\begin{array}{c}6 \\
\\
13.04 \\
39.13\end{array}$ \\
\hline $\begin{array}{l}\text { EATC1E03 } \\
\left(\mathrm{F}_{S T}=0.11\right)\end{array}$ & $\begin{array}{l}\mathrm{n}_{a} \\
\mathrm{H}_{o} \\
\mathrm{H}_{e} \\
\text { ANR } \\
\text { ASL }\end{array}$ & $\begin{array}{c}4 \\
0.25 \\
0.34\end{array}$ & $\begin{array}{c}5 \\
0.44 \\
0.46\end{array}$ & $\begin{array}{c}6 \\
0.37 \\
0.52\end{array}$ & $\begin{array}{c}5 \\
0.44 \\
0.61\end{array}$ & $\begin{array}{l}5.00(0.82) \\
0.38(0.09) \\
0.48(0.11)\end{array}$ & $\begin{array}{l}15.48 \\
46.45\end{array}$ \\
\hline $\begin{array}{l}\text { Set } \mathrm{T} \\
\left(\mathrm{F}_{S T}=0.04,\right. \\
\text { s.e. }=0.06) \\
\text { SpAGC1 } \\
\left(\mathrm{F}_{S T}=0.01\right)\end{array}$ & $\begin{array}{l}\mathrm{n}_{a} \\
\mathrm{H}_{o} \\
\mathrm{H}_{e} \\
\mathrm{n}_{a} \\
\mathrm{H}_{o} \\
\mathrm{H}_{e} \\
\text { ANR } \\
\text { ASL }\end{array}$ & $\begin{array}{c}5.00(1.00) \\
0.32(0.08) \\
0.41(0.06) \\
11 \\
0.51 \\
0.52\end{array}$ & $\begin{array}{c}5.00(1.00) \\
0.35(0.14) \\
0.47(0.01) \\
9 \\
0.54 \\
0.51\end{array}$ & $\begin{array}{c}5.67(0.58) \\
0.35(0.16) \\
0.49(0.04) \\
12 \\
0.56 \\
0.58\end{array}$ & $\begin{array}{c}5.33(0.58) \\
0.38(0.08) \\
0.55(0.08) \\
9 \\
0.59 \\
0.52\end{array}$ & $\begin{array}{c}10.25(1.50) \\
0.55(0.03) \\
0.53(0.03)\end{array}$ & $\begin{array}{c}19 \\
\\
13.48 \\
26.97\end{array}$ \\
\hline $\begin{array}{l}\mathrm{SpAGC2} \\
\left(\mathrm{F}_{S T}=0.00\right)\end{array}$ & $\begin{array}{l}\mathrm{n}_{a} \\
\mathrm{H}_{o} \\
\mathrm{H}_{e} \\
\text { ANR } \\
\text { ASL }\end{array}$ & $\begin{array}{c}13 \\
0.50 \\
0.86\end{array}$ & $\begin{array}{c}12 \\
0.45 \\
0.85\end{array}$ & $\begin{array}{c}12 \\
0.36 \\
0.85\end{array}$ & $\begin{array}{c}13 \\
0.65 \\
0.82\end{array}$ & $\begin{array}{c}12.50(0.58) \\
0.49(0.12) \\
0.84(0.02)\end{array}$ & $\begin{array}{l}15.62 \\
31.24\end{array}$ \\
\hline $\begin{array}{l}\text { SpAGG3 } \\
\left(\mathrm{F}_{S T}=0.03\right)\end{array}$ & $\begin{array}{l}\mathrm{n}_{a} \\
\mathrm{H}_{o} \\
\mathrm{H}_{e} \\
\text { ANR } \\
\text { ASL }\end{array}$ & $\begin{array}{c}15 \\
0.81 \\
0.89\end{array}$ & $\begin{array}{c}16 \\
0.83 \\
0.88\end{array}$ & $\begin{array}{c}14 \\
0.81 \\
0.89\end{array}$ & $\begin{array}{c}15 \\
0.86 \\
0.89\end{array}$ & $\begin{array}{c}15.00(0.82) \\
0.83(0.03) \\
0.89(0.01)\end{array}$ & $\begin{array}{c}21 \\
\\
19.77 \\
39.54\end{array}$ \\
\hline $\begin{array}{l}\text { SpAGD1 } \\
\left(\mathrm{F}_{S T}=0.02\right)\end{array}$ & $\begin{array}{l}\mathrm{n}_{a} \\
\mathrm{H}_{o} \\
\mathrm{H}_{e} \\
\text { ANR } \\
\text { ASL }\end{array}$ & $\begin{array}{c}29 \\
0.82 \\
0.95\end{array}$ & $\begin{array}{c}19 \\
0.84 \\
0.89\end{array}$ & $\begin{array}{c}29 \\
0.63 \\
0.95\end{array}$ & $\begin{array}{c}27 \\
0.89 \\
0.93\end{array}$ & $\begin{array}{c}26.00(4.76) \\
0.79(0.11) \\
0.93(0.03)\end{array}$ & $\begin{array}{l}28.51 \\
57.02\end{array}$ \\
\hline $\begin{array}{l}\mathrm{SpAC} 1 \mathrm{H} 8 \\
\left(\mathrm{~F}_{S T}=0.02\right)\end{array}$ & $\begin{array}{l}\mathrm{n}_{a} \\
\mathrm{H}_{o} \\
\mathrm{H}_{e} \\
\text { ANR } \\
\text { ASL }\end{array}$ & $\begin{array}{c}22 \\
0.70 \\
0.93\end{array}$ & $\begin{array}{c}19 \\
0.57 \\
0.91\end{array}$ & $\begin{array}{c}22 \\
0.45 \\
0.92\end{array}$ & $\begin{array}{c}20 \\
0.71 \\
0.90\end{array}$ & $\begin{array}{c}20.75(1.50) \\
0.61(0.12) \\
0.91(0.01)\end{array}$ & $\begin{array}{l}21.08 \\
42.17\end{array}$ \\
\hline $\begin{array}{l}\text { SpAC1F7 } \\
\left(\mathrm{F}_{S T}=0.01\right)\end{array}$ & $\begin{array}{l}\mathrm{n}_{a} \\
\mathrm{H}_{o} \\
\mathrm{H}_{e} \\
\text { ANR } \\
\text { ASL }\end{array}$ & $\begin{array}{c}8 \\
0.69 \\
0.58\end{array}$ & $\begin{array}{c}7 \\
0.48 \\
0.56\end{array}$ & $\begin{array}{c}6 \\
0.46 \\
0.48\end{array}$ & $\begin{array}{c}6 \\
0.44 \\
0.51\end{array}$ & $\begin{array}{l}6.75(0.96) \\
0.52(0.12) \\
0.53(0.05)\end{array}$ & $\begin{array}{c}9.43 \\
18.85\end{array}$ \\
\hline $\begin{array}{l}\text { Set } \mathrm{D} \\
\left(\mathrm{F}_{S T}=0.02,\right. \\
\text { s.e. }=0.04) \\
\text { SetD+SetT } \\
\left(\mathrm{F}_{S T}=0.02 \text {, }\right. \\
\text { s.e. }=0.04) \\
\text { Set } \mathrm{C} \\
\left(\mathrm{F}_{S T}=0.11\right)\end{array}$ & $\begin{array}{l}\mathrm{n}_{a} \\
\mathrm{H}_{o} \\
\mathrm{H}_{e} \\
\mathrm{n}_{a} \\
\mathrm{H}_{o} \\
\mathrm{H}_{e} \\
\mathrm{n}_{a} \\
\mathrm{H}_{e} \\
\end{array}$ & $\begin{array}{c}16.33(7.79) \\
0.67(0.14) \\
0.79(0.19) \\
12.56(8.38) \\
0.56(0.21) \\
0.66(0.24) \\
10 \\
0.65\end{array}$ & $\begin{array}{c}13.67(5.13) \\
0.62(0.17) \\
0.77(0.18) \\
10.78(5.95) \\
0.53(0.20) \\
0.67(0.21) \\
12 \\
0.84\end{array}$ & $\begin{array}{c}15.83(8.26) \\
0.55(0.16) \\
0.78(0.20) \\
12.44(8.28) \\
0.48(0.18) \\
0.68(0.21) \\
6 \\
0.47\end{array}$ & $\begin{array}{c}15.00(7.62) \\
0.69(0.17) \\
0.76(0.19) \\
11.78(7.73) \\
0.59(0.21) \\
0.69(0.19) \\
7 \\
0.38 \\
\end{array}$ & $\begin{array}{l}8.75(2.75) \\
0.58(0.20)\end{array}$ & \\
\hline
\end{tabular}

$\mathrm{n}_{a}=$ observed number of alleles; $\mathrm{H}_{O}=$ observed hereozigosity; $\mathrm{H}_{e}=$ Nei's expected heterozygosity (Nei, 1973); $\mathrm{F}_{S T}=$ Weir and Cockeram's (1984) $\mathrm{F}_{S T}$; ANR = Average Number of Repeats; ASL = Average Stretch Length. F = Fusine; T= Tarvisio; V = Val di Fiemme; M = Val Meledrio. Standard deviations in parentheses 
Table II. (a) Two-way ANOVA for the natural logarithm of the within-population variance of microsatellite loci. (b) Ratios of mutation rates relative to the least variable nuclear marker set (set $\mathrm{T}$ ). (c) Synopsis of statistical significance at the 5\% level of measures of population differentiation. Each triangular matrix corresponds to one genetic measure.

\begin{tabular}{|c|c|c|c|c|c|}
\hline \multicolumn{6}{|l|}{ (a) } \\
\hline Factor & $\begin{array}{l}\text { Sum } \\
\text { of squares }\end{array}$ & D.F. & Mean square & $\mathrm{F}$ & $P$ \\
\hline Marker set & 198.95 & 2 & 99.477 & 75.382 & $1.349510^{-13}$ \\
\hline Population & 1.2712 & 3 & 0.42374 & 0.32110 & 0.81004 \\
\hline Interaction & 2.6053 & 6 & 0.43423 & 0.32905 & 0.91724 \\
\hline Residue & 47.507 & 36 & 1.3196 & & \\
\hline
\end{tabular}

\begin{tabular}{|c|c|c|c|c|c|c|c|c|c|}
\hline \multicolumn{10}{|l|}{ (b) } \\
\hline Set D & Set ' & \multicolumn{8}{|c|}{ Set C } \\
\hline 8.49 & 1.00 & \multicolumn{8}{|c|}{$7.3310^{-2}$} \\
\hline \multirow[t]{2}{*}{$\overline{\text { (c) }}$} & \multirow{2}{*}{\multicolumn{4}{|c|}{$\mathrm{R}_{S T}$}} & \multirow[b]{3}{*}{ SetD+SetT } & \multicolumn{4}{|c|}{$\mathrm{R}_{S T}$} \\
\hline & & & & & & & & & \\
\hline Set D & $\mathrm{F}$ & $\mathrm{T}$ & V & M & & $\mathrm{F}$ & $\mathrm{T}$ & V & M \\
\hline $\mathrm{F}$ & & - & - & - & $\mathrm{F}$ & & - & - & - \\
\hline $\mathrm{T}$ & + & & - & + & $\mathrm{T}$ & - & & - & + \\
\hline $\mathrm{V}$ & + & + & & - & V & + & - & & + \\
\hline M & + & + & + & & $\mathrm{M}$ & + & + & + & \\
\hline Set $T$ & F & $\mathrm{T}$ & V & M & Set C & $\mathrm{F}$ & $\mathrm{T}$ & V & M \\
\hline $\mathrm{F}$ & & - & - & - & F & & - & - & - \\
\hline $\mathrm{T}$ & - & & - & - & $\mathrm{T}$ & - & & - & - \\
\hline V & - & - & & - & V & + & + & & - \\
\hline M & + & + & + & & M & + & + & + & \\
\hline
\end{tabular}

"+": significantly different from zero; "-": non significant. $\mathrm{F}=\mathrm{Fu}-$ sine; $\mathrm{T}=$ Tarvisio; $\mathrm{V}=$ Val di Fiemme; $\mathrm{M}=$ Val Meledrio. Set $\mathrm{D}=$ dinucleotide nuclear markers; set $\mathrm{T}=$ trinucleotide nuclear markers; set $\mathrm{C}=$ chloroplast markers.

alleles may contribute to apparent excess homozygosity, but in this case we would expect to detect it within population as well as in the whole sample.

For the subsequent analyses, the microsatellite loci have been subdivided in three sets according to their features: set $\mathrm{D}$, including the dinucleotide SSRs; set T, including the trinucleotide SSRs; set C, with the chloroplast SSRs. This allowed us to study the effects of the repeat type and of the mode of inheritance on the power of detection of differentiation.

The assignment of markers to sets is also supported by the analysis of variance of allele sizes, which allows the measurement of ratios of mutation rates between loci. In this analysis, locus Pt30204 was excluded because it was monomorphic in three populations out of four. As shown in Figure 1b, the differences in variance (and therefore in mutation rate) are significant across sets of markers. The distribution of variances was tested for normality through a Kolmogorov-Smirnov test. Homogeneity of variances was tested through a Bartlett test (both tests showed no significant value).

Table II(a) shows the partition of variance, proving that the effect due to partition into marker sets is significant, while there is neither population nor interaction effect. Therefore differences in variance are only caused by mutational properties of loci. Table II(b) shows ratios of mutation rates relative to the least variable nuclear marker set (set T). Differences in mutation rate are 8-fold between the set $\mathrm{D}$ and the set T. Mutation rate in set $\mathrm{C}$ is one order of magnitude smaller than in set $\mathrm{T}$ and two orders of magnitude smaller that in set D. Chloroplast markers appear to be much less variable than nuclear ones; nevertheless, chloroplast haplotype diversity is comparable to diversity at nuclear loci.

We also investigated the relationship between microsatellite repeat length and population variation. Since we have previously shown that SSR variance is independent of population history (see the results of the ANOVA analysis), we can take differences in population variability across markers as a hint of differences in mutational features. Dinucleotide markers display significant correlation $\left(R^{2}=0.702, P<0.05\right)$ between average allele size (averaged over the entire sample, and expressed either as number of repeats, ANR, or as length of the microsatellite stretch in nucleotides, ASL) and population variability $\left(\mathrm{H}_{e}\right)$ (Tab. I), thus indicating that mutability is somehow related to the length of the repeat. Nevertheless, we cannot deduce whether variability is actually related to the number of repeats or to the absolute size of the stretch. As pointed out by Ellegren [5] the mutability of SSRs may depend on the formation of loops in the DNA during replication, and this would depend on absolute microsatellite length rather than on the number of repeats. Consequently, trinucleotide and dinucleotide SSRs with different repeat number but equivalent length should undergo similar mutational processes and therefore display comparable levels of variability. To test this, we grouped set D and set $\mathrm{T}$ in a correlation analysis. Under Ellegren's hypothesis, we should have found positive correlation of variability with absolute length of the microsatellite, but not with repeat number. The analyses performed on our data set produced a rather different pattern, with $\mathrm{N}_{e}$ (not shown) correlating significantly to repeat number but not to absolute length of the microsatellite stretch, and $\mathrm{H}_{e}$ showing no significant correlation, but with $P$-value far smaller for repeat number than for absolute length. Our results seem to point to different mutational features than those put forward by Ellegren [6].

The reliability of the two measures of genetic distance, computed on the three sets of markers, has been tested by comparison to the expected pattern of differentiation.

We expected to observe higher levels of differentiation for pairs of distant populations (Tarvisio-Val Meledrio, TarvisioVal di Fiemme, Fusine-Val Meledrio, and Fusine-Val di Fiemme) than for pairs of closer populations (Tarvisio-Fusine and Val Meledrio-Val di Fiemme). It was also expected that the couple Val Meledrio-Val di Fiemme showed a higher degree of differentiation than Fusine-Tarvisio, due to the larger distance within the former pair. This expectation is based on the data obtained on an independent set of populations by a set of markers partially overlapping those applied to the present study (F. Magni, unpublished results). As it is shown in Figure $1 \mathrm{c}$, at short to medium distances $(0-200 \mathrm{~km})$ there is correlation between genetic and geographical distances, with $R^{2}=$ 0.242 , while the fitting straight line flattens at larger distances. According to Hedrick [11], this implies lack of migration-drift equilibrium at long, but not at short to middle, distances. 
Table II(c) shows patterns of statistical significance for combinations of markers and genetic distance measures. Globally, set D showed more significant pairwise comparisons than set $\mathrm{T}$ (7 against 3). As expected from the theoretical background, $\mathrm{F}_{S T}$ produced more significant comparisons than $\mathrm{R}_{\mathrm{ST}}$, since the former parameter is more sensitive to genetic drift and gene flow while the latter is more sensitive to mutation [8]. F $_{\text {ST }}$ 's significance level increased along with allelic (or haplotypic) diversity, with chloroplast haplotypes producing exactly the expected pattern of differentiation. Set T highlighted the separation of the Val Meledrio stand from all the others, probably reflecting the peculiar distribution of one allele (allele 140 of marker EATC1E03). $\mathrm{R}_{\mathrm{ST}}$ was generally insensitive to marker variability, since only one comparison was significant for set $\mathrm{D}$, and none for set $\mathrm{T}$. When all the nuclear loci were combined together, $\mathrm{F}_{\mathrm{ST}}$ displayed intermediate results between set $\mathrm{D}$ and set $\mathrm{T}$. $\mathrm{R}_{\mathrm{ST}}$, instead, showed more significant comparisons than for each set taken separately, highlighting some sensitivity to locus sampling. However, AMOVA analyses did not support any geographical structuring for any combination of markers and genetic distance measure.

The distribution of chloroplast haplotypes was also investigated by the construction of a haplotype network. One of the possible alternative networks is shown in Figure 1d. This connection scheme was chosen following two assumptions: (i) the most frequent haplotypes are likely to be older, and therefore are placed at the centre of the network [28]; and (ii) the distance from central haplotypes is minimised for each haplotype. Departures form random distribution of haplotypes relative to geographical distribution of population was tested but no significant result was found, although in general the Western populations tend to retain only the most frequent, "central" haplotypes. This is also reflected in genetic diversity parameters computed on the chloroplast data set (Tab. I), showing a higher level of variability for Eastern than for Western populations. The same does not hold true when nuclear loci are considered.

\section{DISCUSSION}

In this paper we have compared the features of different classes of microsatellite markers in Norway spruce, and evaluated their performances in the detection of genetic variability and differentiation in a small-scale population survey, with populations chosen at increasing geographical distance. Microsatellite classes differed at least in their level of variability, and in their power in separating populations or groups of populations. Dinucleotide stretches are the most variable ones, trinucleotide markers have intermediate variability, chloroplast mononucleotides appear to be the most stable group. Variability and mutation rates positively correlate, while population history proved to have no statistically significant effects on marker variability, in spite of the fact that some markers highlight differentiation among populations. Indeed, for population history to have detectable effects on variability, genetic bottlenecks should take place, which is seldom - if ever - observed for Norway spruce. Our data also tentatively suggest that diversity positively correlates to average number of repeats, but not to absolute fragment length of repeat stretches, in contrast with Ellegren's [6] hypotheses on the origin of SSR mutations. It seems therefore that the loci analysed here conform more to in vitro experiments on microsatellite mutability than do human loci discussed in Doyle and Doyle [5], although our data do not allow us to make hypotheses on molecular mechanisms behind this property. Care must be taken, however, with this conclusion, since trinucleotide repeats tend to be more imperfect than dinucleotide ones and therefore the derivation of repeat number and stretch length from fragment size may be far from accurate.

Markers derived from the nuclear genome detected no differences between populations as far as genetic diversity is concerned; on the other hand, chloroplast haplotypes showed that Western populations are less variable than Eastern ones (Tab. I and Fig. 1d). Although this could not be proven statistically, it is reasonable to ascribe this difference to differences in effective population size between nuclear and cytoplasmic genomes, which make the latter more sensitive than the former to historical variations in deme size. Moreover, the lower chloroplast mutation rate slows recovery of genetic diversity after deme size variations.

Differences arose between dinucleotide and trinucleotide markers in the identification of population fragmentation, since only markers EATC1B02 and EATC1E03 showed hints of Wahlund effect. None of the dinucleotide markers did, because in this case heterozygote defect was observed for most of the single populations and at the global level (possibly due to the presence of null alleles). In general, $\mathrm{F}_{\mathrm{ST}}$ values derived from these markers were very small, as expected for populations of Norway spruce lying so close to each other. Figure 1c suggests that, at larger distances, $F_{S T}$ values obtained with SSR markers are not particularly smaller than for markers showing less within-population variability.

Genetic distance measures produced variable patterns of differentiation. Chloroplast SSRs matched what we considered the most realistic situation when combined with $\mathrm{F}_{\mathrm{ST}}$, while other combinations show that significance increases with variability, rather than decreasing as theoretically expected $[10,32]$. The explanation may come from the fact that, for microsatellites, mutation, which is more frequent in more variable markers, has sizeable effects even over short time spans, combining with drift; moreover, microsatellites are known not to follow the Infinite Allele Model on which $\mathrm{F}_{\mathrm{ST}}$ relies.

It is interesting that, in one case, the differentiation pattern appeared to be determined essentially by the highly skewed distribution of one allele (combination set $\mathrm{T} / \mathrm{F}_{\mathrm{ST}}$ ). This suggests that, in some cases, the patterns of differentiation of single alleles may stand out against an indistinct background determined by the other alleles and loci. Single-allele analyses may therefore be of some help [30].

Although the sample sizes involved in this study were relatively small, and do not allow to draw general inferences, they are likely to represent a real-case situation, frequently encountered in population genetic surveys or in conservation-related cases. Therefore our analysis can be taken as a reflection on the use of different classes of markers for Norway spruce in particular, but also in general. The results reported here highlight 
the importance of testing the power of genetic markers in detecting differentiation, and the need for assessing the statistical significance of results, in studies of population genetics, evolution and conservation. In particular, we highlight that the wrong choice of marker/parameter combination can lead to over- or under-estimates of actual patterns of population differentiation, an occurrence that is seldom taken into account by practitioners when drawing inferences from data. Our results stress the importance of introducing "reference" data sets in population studies, in order to define the sensitivity of the tools used to detect differentiation.

\section{REFERENCES}

[1] Balloux F., Lugon-Moulin N., The estimation of population parameters with microsatellite markers, Mol. Ecol. 11 (2002) 155-165.

[2] Bucci G., Vendramin G.G., Delineation of genetic zones in the European Norway spruce natural range: preliminary evidence, Mol. Ecol. 9 (2000) 923-934.

[3] Burczyk J., Lewandowski A., Chalupka W., Local pollen dispersal and distant gene flow in Norway spruce (Picea abies [L.] Karst.), For. Ecol. Manage. 197 (2004) 39-48.

[4] Chakraborty R., Kimmel M., Stivers D.N., Davison L.J., Deaka R., Relative mutation rates at di-, tri-, and tetranucleotide microsatellite loci, Proc. Natl. Acad. Sci. USA, 94 (1997) 1041-1046.

[5] Doyle J.J., Doyle J.L., Isolation of plant DNA from fresh tissue, Focus 12 (1990) 13-15.

[6] Ellegren H., Heterogeneous mutation processes in human microsatellite DNA sequences, Nat. Genet. 24 (2000) 400-402.

[7] Excoffier L., Smouse P.E., Quattro J.M., Analysis of molecular variance inferred from metric distances among DNA haplotypes: application to human mitochondrial DNA restriction data, Genetics 131 (1992) 479-491.

[8] Goldstein D.B., Pollock D.D., Launching microsatellites: a review of mutation processes and methods of phylogenetic inference, J. Hered. 88 (1997) 335-342.

[9] Gugerli F., Sperisen C., Buchler U., Magni F., Geburek T., Jeandroz S., Senn J., Haplotype variation in a mitochondrial tandem repeat of Norway spruce (Picea abies) populations suggests a serious founder effect during postglacial re-colonization of the western Alps, Mol. Ecol. 10 (2001) 1255-1263.

[10] Hartl D.L., Clark A.G., Principles of population genetics, 3rd ed., Sinauer Associates, Sunderland, MA, 1997.

[11] Hedrick P.W., Perspective: highly variable loci and their interpretation in evolution and conservation, Evolution 53 (1999) 313-318.

[12] Hutchinson D.W., Templeton A.R., Correlation of pairwise genetic and geographic distance measures: inferring the relative influence of gene flow and drift on the distribution of genetic variability, Evolution 53 (1999) 1898-1914.

[13] Kimura M., Crow J.F., The number of alleles that can be maintained in a finite population, Genetics 49 (1978) 725-738.

[14] Kimura M., Ohta T., Stepwise mutation model and distribution of allelic frequencies in a finite population, Proc. Natl. Acad. Sci. USA 75 (1978) 2868-2872.

[15] Lagercrantz U., Ryman N., Genetic structure of Norway spruce (Picea abies): concordance of morphological and allozymic variation, Evolution 44 (1990) 38-53.
[16] Lewontin R.C., Krakauer J., Distribution of gene frequency as a test of the theory of the selective neutrality of polymorphisms, Genetics 74 (1973) 175-195.

[17] Morgante M., Vendramin G.G., Rossi P., Olivieri A.M., Selection against inbreds in early life-cycle phases in Pinus leucodermis Ant., Heredity 70 (1993) 622-627.

[18] Nei M., Analysis of genetic diversity in subdivided populations. Proc. Natl. Acad. Sci. USA 70 (1973) 3321-3323.

[19] Pfeiffer A., Olivieri A.M., Morgante M., Identification and characterisation of microsatellites in Norway spruce (Picea abies K.), Genome 40 (1997) 411-419

[20] Raymond M., Rousset F., GENEPOP (version 1.2): population genetics software for exact tests and ecumenicism, J. Hered. 86 (1995) 248-249.

[21] Schneider S., Kueffer J.-M., Roessli D., Excoffier L., ARLEQUIN ver. 1.1: A software for population genetic data analysis, Genetics and Biometry Laboratory, University of Geneva, Switzerland, 1997.

[22] Scotti I., Magni F., Fink R., Powell W., Binelli G., Hedley P.E., Microsatellite repeats are not randomly distributed within Norway spruce (Picea abies K.) expressed sequences, Genome 43 (1999) $41-46$.

[23] Scotti I., Magni F., Paglia G.P., Morgante M., Trinucleotide microsatellites in Norway spruce (Picea abies): their features and the development of molecular markers, Theor. Appl. Genet. 104 (2002) 1035-1041.

[24] Scotti I., Paglia G.P., Magni F., Morgante M., Efficient Development of Dinucleotide microsatellite markers in Norway spruce (Picea Abies Karst.) through dot-blot selection, Theor. Appl. Genet. 106 (2002) 40-50.

[25] Scotti I., Vendramin G.G., Matteotti L.S., Scarponi C., Sari-Gorla M., Binelli G., Postglacial recolonization routes for Picea abies K. In Italy as suggested by the analysis of sequence-characterized amplified region (SCAR) markers, Mol. Ecol. 9 (2000) 699-708.

[26] Slatkin M., A measure of population subdivision based on microsatellite allele frequencies, Genetics 139 (1995) 157-162.

[27] Sperisen C., Buchler U., Gugerli F., Matyas G., Geburek T., Vendramin G.G., Tandem repeats in plant mitochondrial genomes: application to the analysis of population differentiation in the conifer Norway spruce, Mol. Ecol. 10 (2001) 257-263.

[28] Templeton A.R., Nested clade analyses of phylogeographic data: testing hypotheses about gene flow and population history, Mol. Ecol. 7 (1998) 381-397.

[29] Templeton A.R., Routman E., Phillips C.A., Separating population structure from population history: a cladistic analysis of the geographical distribution of mitochondrial DNA haplotypes in the tiger salamander, Ambystoma tigrinum, Genetics 140 (1995) 767-782.

[30] Turgeon J., Bernatchez L., Clinal variation at microsatellite loci reveals historical secondary intergradation between glacial races of Coregonus artedi (Teleostei: Coregoninae), Evolution 55 (2001) 2274-2286.

[31] Vendramin G.G., Lelli L., Rossi P., Morgante M., A set of primers for the amplification of 20 chloroplast microsatellites in Pinaceae, Mol. Ecol. 5 (1996) 595-598.

[32] Waples R.S., Separating the wheat from the chaff: patterns of genetic differentiation in high gene flow species, J. Hered 89 (1998) 438-450.

[33] Weir B.S., Cockeram C.C. (1984) Estimating F-statistics for the analysis of population structure, Evolution 38 (1984) 1358-1370.

[34] Yeh F.C., Yang R.-C., Boyle T., POPGENE Version 1.21, University of Alberta, 1997. 